\title{
Coping with the human factor
}

The Soviet authorities displayed considerable $\mid$ Now the evidence presented at the meeting is candour in Vienna last week. "Gross human being sifted for the lessons that will need to be error" was blamed for the Chernobyl accident. well learned if the industry is to have a future.

\section{Search for extra safety}

By the time the operators of the Chernobyl Number 4 reactor pressed the SCRAM button to close it down it was already too late. That is one of the conclusions of the modelling studies by which Soviet scientists have simulated the course of events leading up to the accident. The simulations show that uranium oxide fuel elements in the upper part of the core had already begun to disintegrate as a consequence of the high temperatures they had reached. In the event, the downward movement of the control rods actuated by the SCRAM button, called AZ-5 on the control panel, was halted half-way along their track, presumably by a mechanical obstruction of some kind. Although the operators disconnected the control rods from their servo-motors with the objective of letting them fall freely, within 20 seconds an explosion within the reactor vault ended the useful life of the reactor.

By the account given by the Soviet delegation in Vienna last week, this was the culmination of 24 hours of frustration in the Chernobyl control room, whose occupants were 12 hours later than planned with a live test of a scheme for extracting emergency electric power from one of the station's two turbo-generating sets. The test had been carried out on two previous occasions, in 1982 and 1984 . The plan, on 25 April this year, was to use the impending shut-down of the Number 4 reactor (for routine maintenance) as an opportunity for a further test.

The objective was laudable enough, to bridge the gap that could arise if a reactor was accidentally isolated from the power grid. Even shut-down reactors need external power for circulating coolant that will carry away heat from radioactive fission products accumulated in the fuel. At Chernobyl as at other reactors, there were stand-by arrangements for supplying emergency electric power, storage batteries and three $5,500 \mathrm{~kW}$ diesel generators. But the storage batteries would have sufficed only to keep the instrumentation, control panels and some control systems operating, and would not have been powerful enough to drive the cooling pumps.

Using the energy of a decaying turbine set, which may amount to several megawatt-seconds, to fill this gap seems a prudent preparation for emergencies. The technical problem is to ensure that the power is supplied at a sufficient voltage (6 $\mathrm{kV}$ at Chernobyl) for as long as possible. According to Soviet statements in Vienna last week, there is, even so, "much discus. sion in the Soviet Union of the necessity of these tests".

The planning of the tests seems to have been in tune with the general sloppiness of the operation of the control room at the end of April. Because the two earlier tests had shown the voltage to fall more rapidly than expected, the electromagnetic loading of the generators had been modified. But the test planned for 25 April was otherwise to be a straightforward repetition of the two earlier tests. The planning of the tests had been delegated to a group from an unidentified "electrotechnical institute" which is apparently not an academic institution but a group of engineers functioning as consulting engineers in the Western sense.

The specification of the test procedure was described as "poor". Specifically, the section of the planning document dealing with safety measures had been "drafted in a purely formal way". The planners had not thought through the dangers that might arise and specified remedies, but had instead advised that, in case of an emergency, the staff should act "in accordance with plant instructions".

In spite of its intrinsic defects, the plan for the test survived the scrutiny that, according to Academician V.A. Legasov, head of the Soviet delegation, is customary on these occasions because it bypassed the normal procedures. In particular, the plan was not shown to the design group responsible for RBMK reactors, which is a "violation of regulations". Because the plan required that the emergency core cooling system should be shut off, the implication is that it would have been given short shrift if it had gone beyond the chief engineer's desk.

The Soviet accident report says that because safety considerations had been skimped in the planning of the test, "the staff involved were not adequately prepared . . . and were not aware of the possible dangers". This is not an absolution for the staff, which is charged not merely with departing from the programme but with breaking the station's safety regulations in the process.

In the sequel, the catastrophic explosion of the reactor, the test of the spinning-down of the turbo-generator as a source of emergency power featured in two ways that are not fully explained by last week's statements. First, the operating crew appears to have believed that it might be necessary to carry out at least one repetition of the test (which is why an attempt was made to keep the reactor operating at low power). Second, the crew seems not to have realized that they could have carried through a single test at any time, thereby avoiding trouble, simply by allowing the safety system to close down the reactor. 